\title{
SECAGEM DA POLPA DE GRAVIOLA (ANNONA MURICATA L.) EM CAMADA DE ESPUMA: AVALIAÇÃO DOS PARÂMETROS DE SECAGEM
}

\author{
C. E. M. R.GURGEL ${ }^{1 *}$, J.T. DIEB ${ }^{3}$, A. K. T. MACHADO ${ }^{3}$, M. F. D. MEDEIROS ${ }^{2}$ \\ ${ }^{1}$ Universidade Federal do Rio Grande do Norte, Pós-Graduação em Engenharia Química \\ ${ }^{2}$ Universidade Federal do Rio Grande do Norte, Departamento de Engenharia Química \\ ${ }^{3}$ Universidade Federal do Rio Grande do Norte, Graduação em Engenharia Química \\ *e-mail: engcamillagurgel@gmail.com
}

\begin{abstract}
RESUMO
A desidratação de produtos alimentícios é um processo amplamente utilizado para melhorar a estabilidade dos alimentos. Neste trabalho, foi estudado o método de desidratação da polpa de graviola em camada de espuma com e sem adição de leite e aditivos (1\% de Super-Liga-Neutra ${ }^{\circledR}$ e $1 \%$ de Emustab $\left.{ }^{\circledR}\right)$, avaliando-se o desempenho do processo, as características do produto obtido e os efeitos da secagem sobre o mesmo. Este processo é de baixo custo e apresenta vantagens sobre outros métodos de desidratação. Os experimentos foram realizados conforme o planejamento experimental $2^{3}$, com 3 repetições no ponto central. Estudaram-se os efeitos da temperatura $\left(50^{\circ} \mathrm{C}\right.$, $60^{\circ} \mathrm{C}$ e $\left.70^{\circ} \mathrm{C}\right)$, espessura da camada $(0,30 \mathrm{~cm}, 0,45 \mathrm{~cm}$ e $0,60 \mathrm{~cm})$ e concentração de leite $(0 \%, 20 \%$ e $40 \%)$ na cinética de secagem, avaliando-se o comportamento das curvas e as características físico-químicas do produto em pó (umidade, acidez, solubilidade e atividade de água). A adição do leite promoveu maior expansão da espuma, facilitando e aumentando as taxas de secagem. Além disso, diminuiu a acidez do produto, todavia prejudicou a reconstituição do pó diminuindo a solubilidade e aumentando o tempo de reconstituição. Com relação aos resultados das análises, a graviola em pó apresentou características adequadas para conservação, com elevada solubilidade do pó e curto tempo de reconstituição. De uma forma geral, as características físico-químicas não sofreram alterações importantes com o processo de secagem em camada de espuma.
\end{abstract}

\section{INTRODUÇÃO}

A desidratação de produtos alimentícios é um processo amplamente utilizado para melhorar a estabilidade dos alimentos através da redução da atividade de água do produto, com consequente redução da atividade microbiológica e minimização de algumas alterações físicas e químicas durante $o$ armazenamento (GURGEL, 2014). Além disso, os processos de secagem são importantes para a indústria alimentícia de uma forma geral, pois permitem a redução de custos com a armazenagem, proporcionam uma maior facilidade no transporte dos alimentos, bem como garantem um maior valor agregado ao produto. Entre as técnicas empregadas tem-se o processo de desidratação em camada de espuma ou foammat drying.

O processo de desidratação em camada de espuma (Foam mat drying), desenvolvido por (MORGAN et al. 1959), apresenta-se como uma alternativa para produção de alimentos em pó por se tratar de um processo simples, de baixo custo, que proporciona secagem rápida com preservação da qualidade do produto (CRUZ, 2013). Devido 
a estas vantagens, $\mathrm{o}$ método tem sido amplamente utilizado em pesquisas com frutas (CHAVES et al. 2013; KANDASAMY et al. 2012). Este tipo de processo consiste, basicamente, de três etapas: da modificação da consistência líquida do suco ou polpa, para uma espuma estável pela adição de agentes espumantes na secagem do material em camada fina; da secagem da espuma; e da pulverização do material desidratado (SILVA FILHO, 2012).

Para a escolha do agente espumante utilizado durante a desidratação em camada de espuma deve-se escolher o agente que promove a maior redução de densidade, pois, a redução da densidade é causada pela incorporação de ar durante a agitação da mistura do suco (ou polpa do produto) com o aditivo, que caracteriza a formação da espuma (THUWAPANICHAYANAN et al. 2008). Emulsionantes são ingredientes que de algum modo contribuem para o aumento da estabilidade das emulsões, podendo ser emulsionantes ou agentes espessantes. Para exercer sua ação, possui na estrutura uma parte hidrofílica que interage com a água, e outra lipofílica, com afinidades por óleo ou substâncias apolares (PAVANELLI, 1998).

O leite é um agente emulsificante, pois apresenta, em sua composição, algumas proteínas específicas que o tornam "formador de espuma". O aditivo comercial Emustab ${ }^{\circledR}$ também apresenta bons resultados como emulsificante, sendo muito utilizado para a formulação das espumas. Os estabilizantes são substâncias hidrocolóides e, portanto, tem uma alta capacidade de retenção de água, o que proporciona uma textura macia e corpo ao produto final (SOLER e VEIGA, 2001). A Super-Liga-Neutra ${ }^{\circledR}$ atua como estabilizante nos alimentos absorvendo e fixando a água livre, retardando a viscosidade, melhorando a textura, conferindo cremosidade e evitando o rápido derretimento.

Neste trabalho estudou-se o processo de secagem da espuma obtida a partir da polpa da graviola, com e sem adição de leite e diferentes formulações pelo processo em camada de espuma - Foam mat. Foram utilizados os adjuvantes Emustab® e SuperLiga-Neutra ${ }^{\circledR}$ nas formulações para expandir e garantir a estabilidade da espuma. O objetivo foi avaliar o efeito da temperatura, da concentração de leite e da espessura da camada de espuma, sobre o desempenho do processo, além de analisar os efeitos da secagem sobre o produto em pó e otimizar as condições da mesma com base nas técnicas de planejamento experimental.

\section{MATERIAIS E MÉTODOS}

Os experimentos foram realizados no Laboratório de Tecnologia de Alimentos da UFRN. Para o desenvolvimento da secagem foram utilizadas as seguintes matérias-primas: polpas pasteurizadas de graviola, leite fluido e aditivos (1\% Emustab® e $1 \%$ Super-LigaNeutra $\left.{ }^{\circledR}\right)$, todos adquiridos no mercado local. Avaliaram-se os efeitos individuais e combinados da temperatura, da concentração de leite e da espessura das camadas de espuma sobre o desempenho do processo.

No preparo da espuma a seguinte metodologia foi adotada: inicialmente a polpa de graviola foi previamente descongelada e pesada, adicionando-se o leite nas proporções $0 \%, 20 \%$ e $40 \%$ e os aditivos nas quantidades pré-definidas; a mistura passou por um processo de agitação constante em batedeira doméstica com duração de 20 minutos, de modo a formar uma espuma com características adequadas à secagem rápida.

$\mathrm{Na}$ Tabela 1 são apresentadas as condições experimentais dos diferentes ensaios de secagem, arranjados de acordo com um delineamento fatorial $2^{3}$, com 3 repetições no ponto central. 
Tabela 1 - Variáveis independentes para os ensaios de secagem em camada de espuma.

\begin{tabular}{cccc}
\hline Ensaios & Leite $(\boldsymbol{\%} \mathbf{p} / \mathbf{p})$ & $\begin{array}{c}\text { Temperatura } \\
\left({ }^{\mathbf{C}}\right)\end{array}$ & $\begin{array}{c}\text { Espessura } \\
(\mathbf{c m})\end{array}$ \\
\hline $\mathbf{0 1}$ & $0(-1)$ & $50(-1)$ & $0,30(-1)$ \\
$\mathbf{0 2}$ & $40(1)$ & $50(-1)$ & $0,30(-1)$ \\
$\mathbf{0 3}$ & $0(-1)$ & $70(1)$ & $0,30(-1)$ \\
$\mathbf{0 4}$ & $40(1)$ & $70(1)$ & $0,30(-1)$ \\
$\mathbf{0 5}$ & $0(-1)$ & $50(-1)$ & $0,60(1)$ \\
$\mathbf{0 6}$ & $40(1)$ & $50(-1)$ & $0,60(1)$ \\
$\mathbf{0 7}$ & $0(-1)$ & $70(1)$ & $0,60(1)$ \\
$\mathbf{0 8}$ & $40(1)$ & $70(1)$ & $0,60(1)$ \\
$\mathbf{0 9}$ & $20(0)$ & $60(0)$ & $0,45(0)$ \\
$\mathbf{1 0}$ & $20(0)$ & $60(0)$ & $0,45(0)$ \\
$\mathbf{1 1}$ & $20(0)$ & $60(0)$ & $0,45(0)$ \\
\hline
\end{tabular}

O fluxograma experimental para obtenção da graviola em pó pelo processo foam-mat encontra-se esquematizado na Figura 1.

Figura 1 - Fluxograma experimental da obtenção de pó de graviola pelo processo de secagem em camada de espuma.

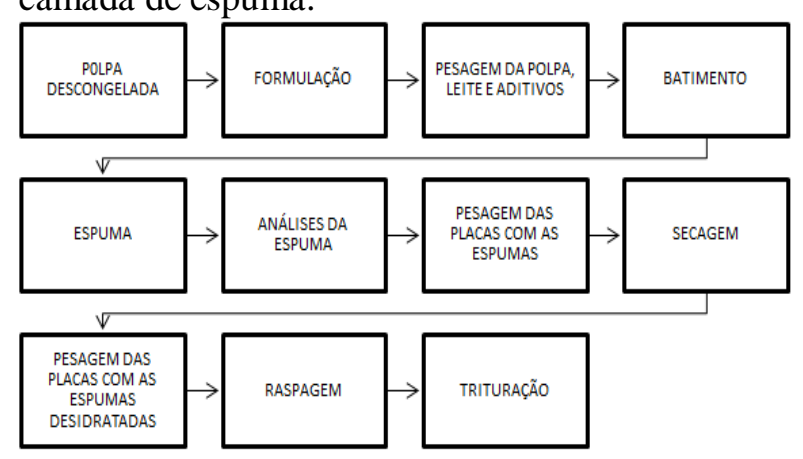

Fonte: Gurgel (2014).

As espumas foram distribuídas em placas de alumínio de igual volume com profundidade e área distintas, processando-se assim o mesmo volume de espuma em camadas de espessura distintas, fixadas nos três níveis do delineamento experimental exibido na Tabela 1. As espumas foram desidratadas em estufa com circulação forçada de ar. A perda de umidade foi acompanhada através da variação do peso das placas ao longo da secagem até que fosse observado peso constante. $\mathrm{O}$ produto desidratado foi retirado das bandejas e triturado em liquidificador doméstico, para obtenção do produto finamente pulverizado. Conforme já descrito em (GURGEL, 2014), considerando a umidade de equilíbrio como a umidade alcançada ao se atingir peso constante, foram calculadas pela Equação 1, para cada conjunto de dados experimentais as razões de umidade (RU). Os dados da razão de umidade, em função do tempo, foram ajustados pelo modelo matemático de Page, representado pela Equação 2, utilizando-se o programa Statistica 7.0.

$$
\begin{aligned}
& R U=\frac{U_{b s}-U_{e q}}{U_{b s i}-U_{e q}} \\
& R U=\exp \left(-k t^{n}\right)
\end{aligned}
$$

De Acordo com (GURGEL, 2014) o modelo de Page apresentou um ótimo ajuste aos dados experimentais e foi utilizado no presente trabalho para predição do tempo necessário para as espumas atingirem uma umidade de $5 \%$ em base seca. Também em (GURGEL, 2014) foi identificado importante período de taxa constante na secagem das espumas, sendo determinada para todos os experimentos a taxa de secagem neste período a partir da quantificação da massa acumulativa de água evaporada por unidade de massa seca em cada intervalo de tempo. O comportamento linear da massa evaporada em função do tempo permitiu a determinação da taxa específica de secagem pela inclinação das retas ajustadas a cada conjunto de dados experimentais. Os dados da taxa específica de secagem no período de taxa constante e o tempo de secagem para as espumas atingirem 5\% de umidade foram analisados no presente trabalho como variáveis respostas relacionadas com a cinética de secagem. 
Os produtos em pó obtidos através da secagem foram submetidos a algumas caracterizações, através dos seguintes métodos analíticos: umidade do pó atingida após a secagem, determinada na balança de infravermelho; a atividade de água medida no analisador de atividade de água (AQUALAB); a acidez total titulável obtida pela titulação com o $\mathrm{NaOH} \quad 1 \mathrm{~N}$; a solubilidade, retirando uma alíquota do sobrenadante após um processo de centrifugação; e o tempo de reconstituição observado a olho nu sob a ação de um agitador magnético. Todas essas caracterizações foram realizadas em triplicata. Os resultados foram analisados como variáveis respostas do planejamento experimental.

A análise estatística dos dados experimentais obtidos em relação à cinética de secagem e caracterização do produto em pó foi executada utilizando-se o programa Statistica, versão 7.0.

\section{RESULTADOS E DISCUSSÕES}

As curvas de secagem da espuma de graviola, representadas pela umidade em base seca em função do tempo, para todas as condições estabelecidas no delineamento experimental são exibidas na Figura 2.

Figura 2 - Curvas de secagem da espuma de graviola com e sem adição de leite.

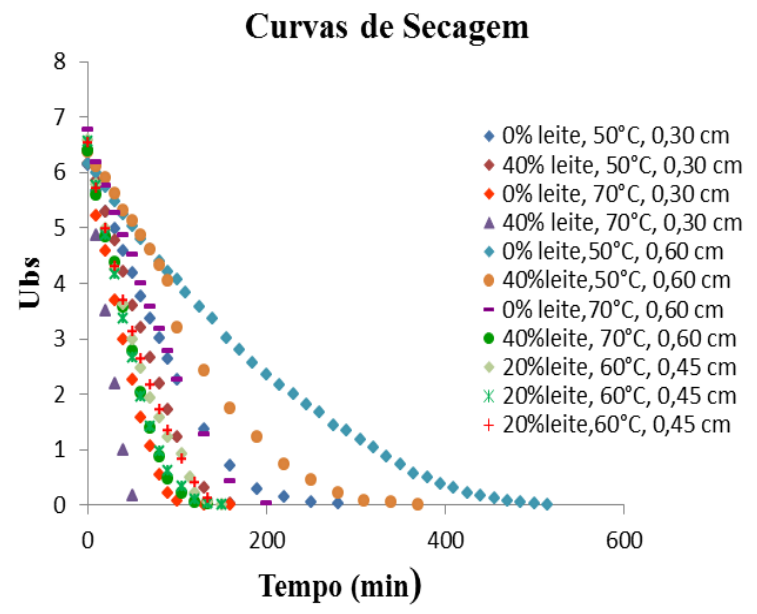

Percebe-se para todas as condições ilustradas que as espumas secaram muito rápido no início do processo, sendo possível visualizar em todas as curvas um importante período de taxa constante. O tempo de secagem para atingir a condição de equilíbrio foi bastante reduzido em função da temperatura, concentração de leite e espessura da camada de espuma. O maior tempo de secagem para atingir o equilíbrio foi de 515 minutos para a temperatura de $50^{\circ} \mathrm{C}$ e espessura de $0,6 \mathrm{~cm}$ sem adição do leite. O menor tempo para atingir o equilíbrio foi 60 minutos para a temperatura de $70^{\circ} \mathrm{C}$ e espessura de $0,3 \mathrm{~cm}$, com adição de $40 \%$ de leite.

Considerando o importante período de taxa constante identificado nas curvas ilustradas na Figura 2, determinou-se para todos os experimentos a taxa de secagem neste período a partir da quantificação da massa acumulativa de água evaporada em cada intervalo de tempo. Foi determinada em cada experimento a massa de sólidos (massa seca) processada e o tratamento dos dados experimentais refere-se à massa específica evaporada (massa evaporada / massa seca).

O comportamento linear da massa específica evaporada em função do tempo evidencia a taxa específica constante de secagem, determinada pela inclinação das retas ajustadas a cada conjunto de dados experimentais.

Os experimentos realizados conforme o planejamento experimental do tipo $2^{3}$ com 3 repetições no ponto central, tendo como variáveis independentes a concentração de leite, a temperatura e a espessura da camada e como variáveis respostas a taxa de secagem no período de taxa constante e o tempo para que a umidade do produto atingisse $5 \%$ em base seca. Este tempo foi estimado para cada experimento utilizando-se as equações ajustadas conforme o modelo de Page. Os resultados obtidos são mostrados na Tabela 2. 
Tabela 2 - Variáveis respostas para a cinética de secagem.

\begin{tabular}{ccc}
\hline Experimento & $\begin{array}{c}\text { Taxa de secagem } \\
\text { (g de água/min) }\end{array}$ & Tempo 5\% (min) \\
\hline $\mathbf{0 1}$ & 0,0390 & 328,64 \\
$\mathbf{0 2}$ & 0,0536 & 235,20 \\
$\mathbf{0 3}$ & 0,0796 & 135,75 \\
$\mathbf{0 4}$ & 0,1398 & 75,53 \\
$\mathbf{0 5}$ & 0,0219 & 686,15 \\
$\mathbf{0 6}$ & 0,0256 & 272,63 \\
$\mathbf{0 7}$ & 0,0456 & 318,77 \\
$\mathbf{0 8}$ & 0,0719 & 177,56 \\
$\mathbf{0 9}$ & 0,0744 & 211,73 \\
$\mathbf{1 0}$ & 0,0782 & 158,38 \\
$\mathbf{1 1}$ & 0,0707 & 213,31 \\
\hline
\end{tabular}

A partir dos resultados obtidos realizouse a análise estatística para verificar os efeitos das variáveis independentes e de suas interações sobre as variáveis respostas. Nos diagramas de Pareto exibidos na Figura 3 (a), (b) e (c) observa-se o efeito da variável independente sobre a resposta analisada será tão significativo quanto mais à direita da linha vermelha ele estiver, no nível de significância de $95 \%$ de confiança.

Figura 3 - Diagramas de Pareto para taxa específica de secagem (a), tempo de secagem para atingir $5 \%$ de umidade (b).

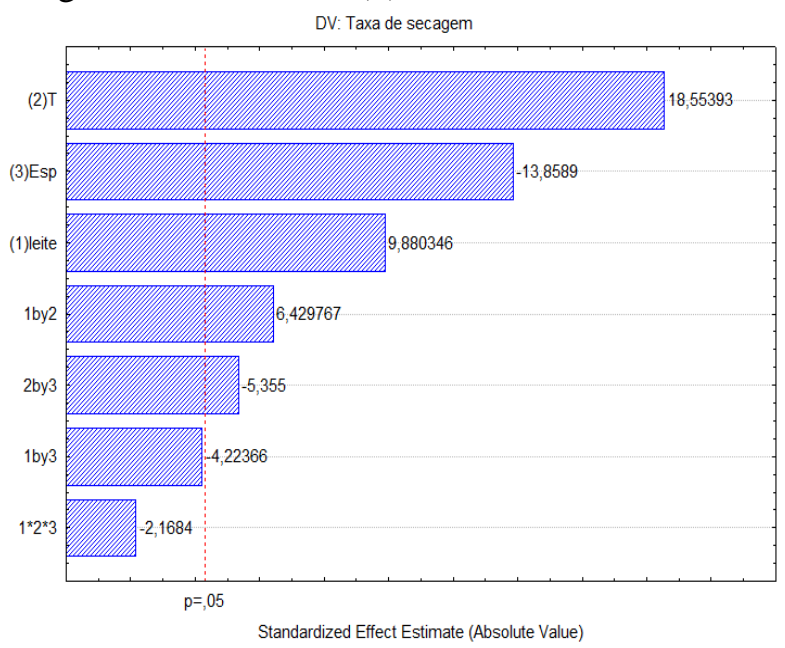

(a) Taxa de secagem

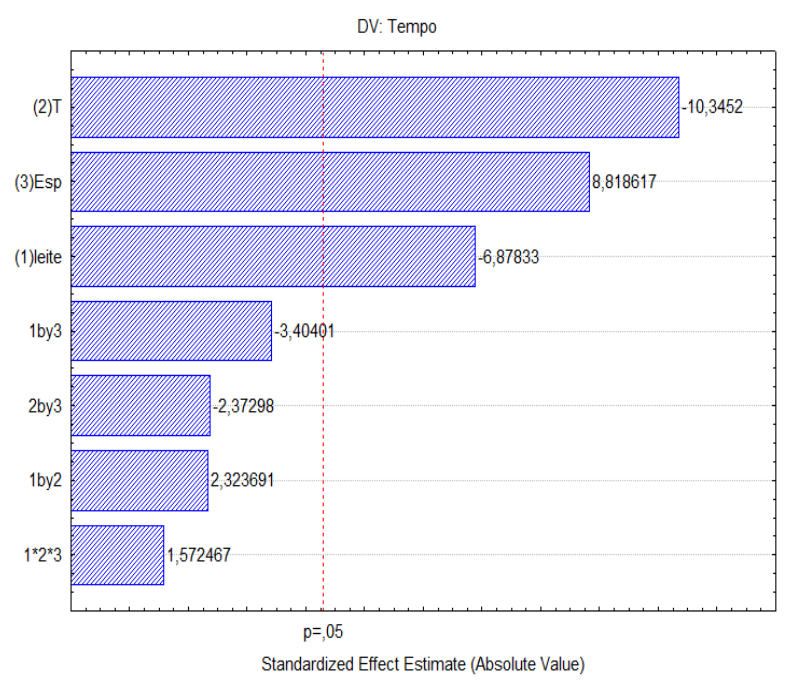

(b) Tempo

Na Figura 3 (a) observa-se que a taxa específica de secagem sofre influência significativa das variáveis independentes e das interações entre as variáveis, concentração de leite $\mathrm{x}$ temperatura $\mathrm{e}$ temperatura $\mathrm{x}$ espessura. A temperatura e a espessura apresentam efeitos contrários, no sentido de aumentar e diminuir a taxa de secagem sendo o efeito da temperatura de maior intensidade. A concentração de leite também apresenta efeito significativo e positivo sobre a taxa de secagem, porém estatisticamente de menor intensidade.

De acordo com o diagrama de Pareto ilustrado na Figura 3 (b) o tempo de secagem para o material atingir 5\% de umidade em base seca é influenciado significativamente apenas pelas variáveis principais, temperatura, espessura e concentração de leite. A temperatura e a concentração de leite apresentam efeito negativo, ou seja, o tempo de secagem é mais curto em temperatura e concentração de leite mais elevadas. $\mathrm{O}$ efeito da temperatura é de maior magnitude do que o da concentração de leite. Inversamente, tempos de secagem mais longos são requeridos quando a camada de espuma é mais espessa. 
Para as variáveis respostas taxa de secagem no período de taxa constante e tempo de processamento para atingir $5 \%$ de umidade foram gerados modelos estatísticos, representados pelas Equações 5 e 6 . Os termos não significativos foram eliminados das equações que correlacionam as variáveis respostas com as variáveis independentes codificadas e com suas interações. As variáveis codificadas são definidas nas Equações 3 e 4.

$T^{*}=\frac{T-60}{10}$

$$
\begin{aligned}
& X^{*}=\frac{X-20}{20} \\
& \mathrm{Taxa}=0,0637+0,0131 \cdot \mathrm{X}_{\text {leite }}^{*}+0,0246 \cdot \\
& \mathrm{T}_{\mathrm{Ar}}^{*}-0,0184 \cdot \varepsilon^{*}+0,0085 \cdot \mathrm{X}_{\text {leite }}^{*} \cdot \mathrm{T}_{\mathrm{Ar}}^{*}-0,0071 \\
& \mathrm{~T}_{\mathrm{Ar}}^{*} \cdot \varepsilon^{*} \\
& t_{p / 5 \%}=264,878-76,048 \cdot X_{\text {leite }}^{*} \\
& 114,376 \cdot T_{A r}^{*}+97,498
\end{aligned}
$$

Para cada modelo representado nas Equações 5 e 6 a significância estatística foi determinada pela análise de variância, e os resultados da análise regressão são mostrados na Tabela 3 .

Tabela 3 - Resultado das Análises de Regressão dos Parâmetros de Secagem.

\begin{tabular}{ccccccccc}
\hline Variável & $\begin{array}{c}\text { Coeficiente } \\
\text { de } \\
\text { Correlação }\end{array}$ & $\begin{array}{c}\text { Qualidade } \\
\text { do } \\
\text { Ajuste }\end{array}$ & $\begin{array}{c}\text { Fcalc } \\
\text { Regressão }\end{array}$ & Ftab & $\begin{array}{c}\text { (Fcal/Ftab) } \\
\text { Regressão }\end{array}$ & $\begin{array}{c}\text { Fcalc } \\
\text { Falta de } \\
\text { Ajuste }\end{array}$ & $\begin{array}{c}\text { Ftab } \\
\text { Falta de } \\
\text { Ajuste }\end{array}$ & $\begin{array}{c}\text { (Fcal/Ftab) } \\
\text { Falta de } \\
\text { Ajuste }\end{array}$ \\
\hline $\begin{array}{c}\text { Taxa de } \\
\text { secagem }\end{array}$ & 0,953 & 0,843 & 29,07 & 5,05 & 5,76 & 7,65 & 19,16 & 0,40 \\
Tempo 5\% & 0,829 & 0,755 & 11,28 & 4,35 & 2,59 & 9,20 & 19,30 & 0,48 \\
\hline
\end{tabular}

De acordo com a Tabela 3, o coeficiente de correlação entre as respostas observadas e os valores preditos pelo modelo estatístico de primeira ordem, ajustado aos dados da taxa de secagem, é de 0,953 . Observa-se que $84,3 \%$ da variação total em torno da média é explicada pela regressão. Com relação ao teste $\mathrm{F}$ de regressão, que verifica se o modelo explica uma quantidade significativa da variação dos dados obtidos pela simulação, o valor de $\mathrm{F}$ é 5,76 vezes superior ao valor tabelado, a um nível de confiança de 95\%, mostrando que a equação ajustada é significativa e útil para fins preditivos.

Em relação ao tempo de secagem para atingir 5\% de umidade, a equação ajustada apresenta um coeficiente de correlação de 0,829 enquanto o valor da qualidade do ajuste é de apenas $75,5 \%$. O valor de F é 2,59 vezes superior ao $\mathrm{F}$ tabelado o que demonstra que o modelo é significativo e útil para fins preditivos.

Realizando-se o teste $\mathrm{F}$ da razão entre as médias quadráticas da falta de ajuste e erro puro, pode-se avaliar se os modelos estão ou não bem ajustado às observações experimentais. Valores altos da razão significam falta de ajuste. Para os dois modelos avaliados os valores de $\mathrm{F}$ exibidos na Tabela 3 são muito inferiores aos valores tabelados, o que demonstra que há um ajuste satisfatório dos mesmos às observações experimentais.

$\mathrm{Na}$ Tabela 4 são apresentadas as características físico-químicas, solubilidade e tempo de reconstituição da graviola em pó. 
Tabela 4 - Características físico-químicas, solubilidade e tempo de reconstituição da graviola em pó.

\begin{tabular}{cccccc}
\hline Ensaios & $\begin{array}{c}\text { Umidade } \\
(\mathbf{\%})\end{array}$ & $\boldsymbol{a} \boldsymbol{w}_{\mathbf{p o ́}}$ & ATT $(\boldsymbol{\%})$ & $\begin{array}{c}\text { Solubilidade } \\
(\mathbf{\%})\end{array}$ & $\begin{array}{c}\text { Tempo } \\
\text { Reconstituição } \\
(\mathbf{s e g})\end{array}$ \\
\hline $\mathbf{0 1}$ & 6,9 & $0,320 \pm 0,004$ & $5,32 \pm 0,02$ & $80,72 \pm 0,81$ & $91 \pm 0,57$ \\
$\mathbf{0 2}$ & 4,2 & $0,310 \pm 0,004$ & $3,22 \pm 0,25$ & $69,81 \pm 0,26$ & $130 \pm 17,32$ \\
$\mathbf{0 3}$ & 3,4 & $0,250 \pm 0,004$ & $5,38 \pm 0,12$ & $83,77 \pm 0,42$ & $90 \pm 0,57$ \\
$\mathbf{0 4}$ & 3,8 & $0,310 \pm 0,007$ & $3,52 \pm 0,10$ & $68,43 \pm 2,33$ & $160 \pm 17,32$ \\
$\mathbf{0 5}$ & 4,9 & $0,350 \pm 0,002$ & $5,43 \pm 0,17$ & $86,97 \pm 0,78$ & $75 \pm 21,21$ \\
$\mathbf{0 6}$ & 4,9 & $0,270 \pm 0,001$ & $3,38 \pm 0,12$ & $71,05 \pm 1,37$ & $160 \pm 17,32$ \\
$\mathbf{0 7}$ & 4,4 & $0,280 \pm 0,005$ & $5,15 \pm 0,25$ & $82,10 \pm 0,82$ & $100 \pm 17,32$ \\
$\mathbf{0 8}$ & 2,8 & $0,280 \pm 0,003$ & $3,43 \pm 0,12$ & $72,66 \pm 0,69$ & $170 \pm 17,32$ \\
$\mathbf{0 9}$ & 6,4 & $0,360 \pm 0,003$ & $4,35 \pm 0,08$ & $76,48 \pm 0,56$ & $140 \pm 17,32$ \\
$\mathbf{1 0}$ & 4,3 & $0,280 \pm 0,006$ & $4,44 \pm 0,13$ & $77,38 \pm 0,20$ & $150 \pm 30,00$ \\
$\mathbf{1 1}$ & 5,9 & $0,270 \pm 0,002$ & $4,06 \pm 0,17$ & $77,56 \pm 0,74$ & $260 \pm 17,32$ \\
\hline
\end{tabular}

Conforme se observa, a umidade do pó variou no intervalo entre $2,8 \%$ e $6,9 \%$ e a atividade de água entre 0,270 e 0,350. Essa variável é muito importante nos estudos de preservação dos alimentos, uma vez que influência no crescimento de bactérias, bolores e leveduras e reações enzimáticas. A estabilidade do alimento com atividade de água (aw) entre 0,2 e 0,4 é elevada, não sendo necessário o uso de conservantes para controlar o crescimento de microrganismos já que a qualidade do produto não é afetada pelo escurecimento não enzimático e pela oxidação de lipídeos. De modo geral, o limite inferior para crescimento microbiano, para todos os microrganismos, é $a w<0,6$ (Rahman, 2008). Estes resultados demonstram que o produto em pó obtido na maioria dos experimentos está em condições adequadas para conservação e armazenamento.

Os resultados mostraram que o pó apresentou solubilidade em água superior a $68,43 \%$, com valor máximo de aproximadamente $86,97 \%$. O tempo de reconstituição foi relativamente curto, variando de um mínimo de 75 segundos a um máximo de 170 segundos. Dantas (2010) utilizando o método de camada de espuma encontrou tempos de reconstituição de $1,5 \mathrm{e}$ 3,5 minutos e solubilidade $98 \%$ e $91 \%$ para os pós de abacaxi e manga respectivamente. A acidez variou entre 3,41 a 5,56\%, diminuindo com adição do leite, conforme esperado. Soares (2001) ao secar polpa de acerola, verificou que o pó apresentou acidez total 7 vezes maior do que a polpa in natura, em torno de $10,24 \%$.

As análises estatísticas dos resultados das caracterizações da graviola em pó foram realizadas através de métodos estatísticos no nível de significância de $95 \%$ de confiança, utilizando-se o programa "Statistica 7.0" de acordo com o planejamento fatorial $2^{3} \mathrm{com}$ três réplicas no ponto central. Os diagramas de Pareto ilustrados na Figura 4 representam o efeito das variáveis independentes sobre as variáveis respostas (a) solubilidade em água, (b) tempo de reconstituição e (c) acidez total titulável respectivamente. Observa-se que apenas a adição de leite, influenciou significativamente nas variáveis respostas 
tempo de reconstituição, solubilidade e acidez total titulável (ATT) do pó produzido.

A adição do leite diminuiu a solubilidade, aumentou o tempo de reconstituição e diminuiu a acidez do pó. As demais variáveis respostas, atividade de água $\left(\mathrm{a}_{\mathrm{w}}\right)$ e umidade do pó não sofreram influência das variáveis independentes ou de suas interações.

Figura 4 - Diagramas de Pareto para a solubilidade em água (a), tempo de reconstituição (b) e acidez total titulável (c).

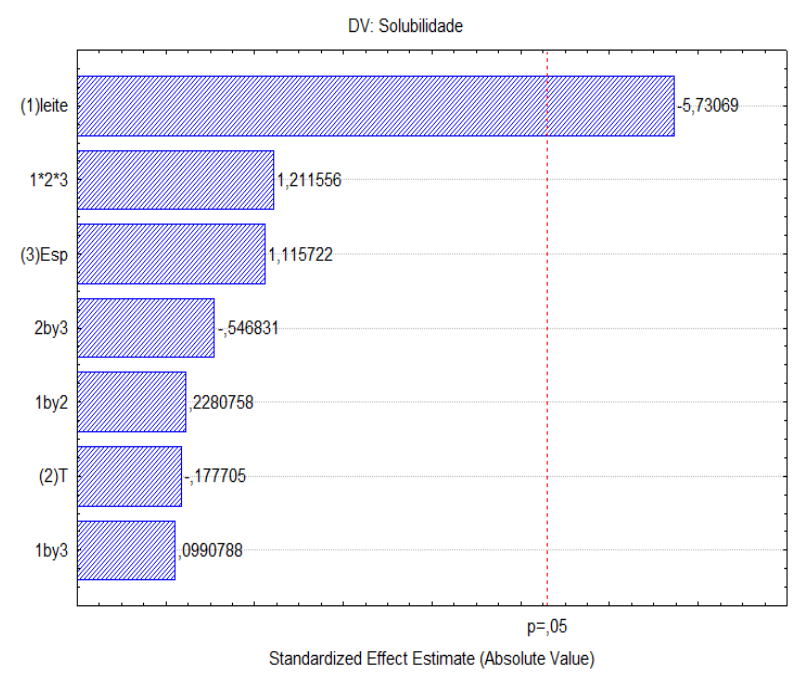

(a) Solubilidade

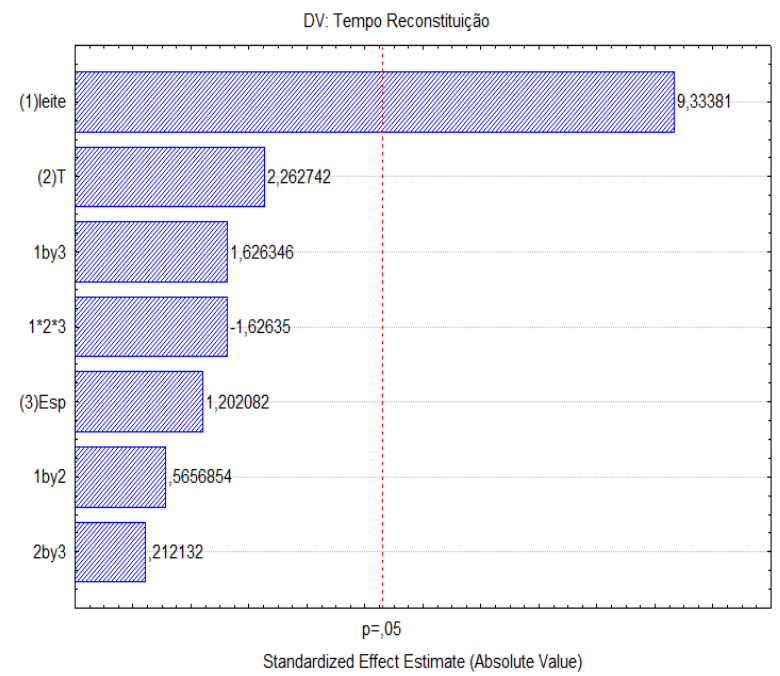

(b) Tempo de Reconstituição

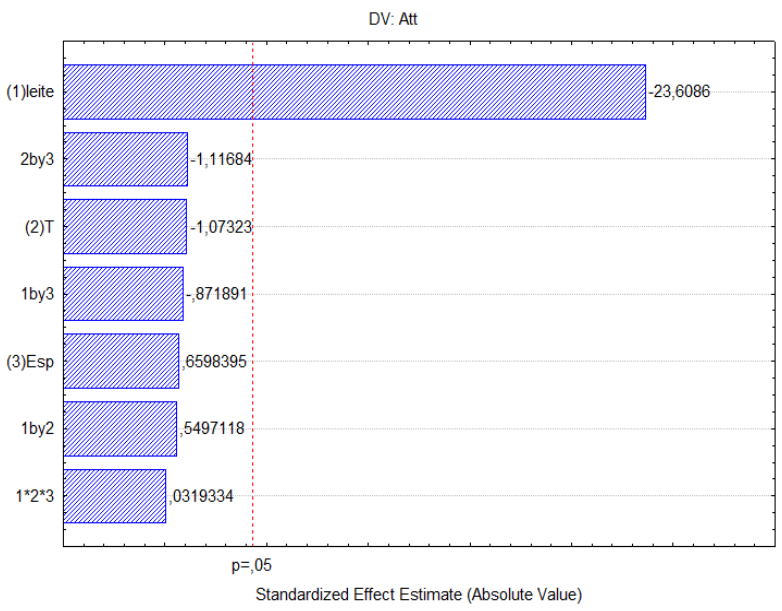

(c) Acidez

Como a temperatura e a espessura ou a interação entre estas variáveis e a concentração de leite não interferiram significativamente nas variáveis respostas, pode-se inferir que o processo de secagem não provocou impacto sobre a solubilidade, tempo de reconstituição e acidez da graviola em pó. Desta forma considera-se desnecessário o aprofundamento do tratamento estatístico com geração de modelos para predição das variáveis respostas em função das variáveis de operação.

\section{CONCLUSÃO}

A secagem da polpa de graviola com adição do leito em camada de espuma apresentou importante período de taxa constante que deve ser considerado em estudos posteriores que visem à otimização do processo, uma vez que neste período as taxas são fortemente influenciadas pelas variáveis externas. Foram obtidos modelos empíricos estatisticamente significativos e preditivos para a taxa específica de secagem no período de taxa constante e para o tempo para atingir 5\% de umidade. Dependendo da combinação das condições de processo, os efeitos contrários das variáveis independentes podem anular o efeito das variáveis individuais o que 
conduz a um estudo de otimização mais rigoroso das condições do processo.

Avaliando os resultados obtidos neste trabalho conclui-se que a adição do leite, dependendo da composição ou propriedades físicas da polpa, pode promover maior expansão da espuma facilitando a desidratação e aumentando as taxas de secagem, todavia, em todos os casos estudados, diminuiu a solubilidade do pó, prejudicando a reconstituição da polpa.

Desta forma, podemos dizer que este processo é viável para produção de pó. Uma vez que de maneira geral as características físico-químicas avaliadas não sofreram alterações importantes com a secagem pelo processo de secagem em camada de espuma.

\section{NOMENCLATURA}

$R U$-Razão de umidade;

$U_{e q^{-}}$umidade de equilíbrio $\left(\mathrm{kg} \quad \mathrm{H}_{2} \mathrm{O} / \mathrm{kg}\right.$ sólido);

$U_{b s^{-}}$umidade em base seca $\left(\mathrm{kg} \mathrm{H}_{2} \mathrm{O} / \mathrm{kg}\right.$ sólido);

$\mathrm{U}_{\mathrm{bsi}}$ - umidade em base seca inicial $(\mathrm{kg}$

$\mathrm{H} 2 \mathrm{O} / \mathrm{kg}$ sólido);

$k$ - constante da equação (1/h);

$\mathrm{n}$ - constante adimensional do modelo de

Page;

$\mathrm{t}$ - tempo (min);

$a w$ - atividade de água;

ATT - acidez total titulável; $t_{p / 5 \%^{-}}$tempo de processamento para atingir 5\% de umidade $\left(\mathrm{kg} \mathrm{H}_{2} \mathrm{O} / \mathrm{kg}\right.$ sólido); Taxa - taxa de secagem no período de taxa constante.

\section{REFERÊNCIAS}

CHAVES, M. A. et al. (2013) Physicochemical and sensory properties of purple Brazilian cherry (Eugenia uniflora, L.) foams. International Journal of Food Science and Technology, 48, 1688-1697.

CRUZ, W.F. Obtenção de polpa de goiaba (Psidium guajava L.) em pó pelo método de secagem em cama da de espuma. Universidade Federal de Viçosa, 2013. (Dissertação de Mestrado).

KANDASAMY P., VARADHARAJU N., KALEMULLAh S., MALADHI D.. Optimization of process parameters for foammat drying of papaya pulp. J Food Sci Technol, 13 August 2012.

GURGEL, C. E. M. R. Secagem da polpa de graviola (Annona muricata L.) em camada de espuma - desempenho do processo e características do produto. Natal, 2014. Dissertação (Mestrado) - Universidade Federal do Rio Grande do Norte. Departamento de Engenharia Química. 80 f.: il.

GURGEL, C. E. M. R.; DIEB, J.T.; MACHADO, I. P.; DANTAS, T. N. P.; CORREIA, T. P.; MEDEIROS, M. F. D. Cinética de secagem da polpa de graviola pelo processo foam-mat. XX Congresso Brasileiro de Engenharia Química. Outubro 2014. Florianópolis/ SC.

MORGAN, A.I., GINNETTE, L.F., RANDALL, J.M. \& GRAHAM, R.P. (1959).Technique for improving instant foods. Food Engineering, 31, 89-94.

PAVANELLI, A. P. Aditivos para panificação: confeitos e funcionalidade. São Paulo: 1998. Associação Brasileira da Indústria de Aditivos e Melhoradores para Alimentos e Bebidas.

Rahman, S. (2008). Food Properties Handbook. CRC Press. 
SILVA FILHO, E. D. Obtenção e avaliação da qualidade da polpa da manga $\mathrm{CV}$. Haden em pó, pelo método de secagem em camada de espuma. Tese (doutorado em Engenharia Agrícola). Campina Grande, 2012. 190f.: il. col.

SOARES, E.C.; OLIVEIRA, G.S.F.; MAIA, G.A.; MONTEIRO, J.C.S.; SILVA Jr., A.S.; FILHO, M.S. Desidratação da polpa de acerola (Malpighia emarginata D.C.) pelo processo foam-mat. Ciência e Tecnologia de Alimentos, Campinas-SP, 2001.

SOLER, M. P.; VEIGA, P. G. Especial: Sorvetes. Série publicações técnicas do centro de informação em alimentos - N.1. [s/local]: ITAL/CIAL, 2001. (ISSN: 1519524).

THUWAPANICHAYANAN, PRACHAYAWARAKORN, R., SOPONRONNARIT, S. (2008a). Drying characteristics and quality of banana foam mat. Journal of Food Engineering, 86, 573 583.

\section{AGRADECIMENTOS}

Agradecimento a CAPES, pelo fornecimento de bolsa para a pesquisa, bem como, a empresa de polpa de frutas IDEAL, pela doação de parte da matéria-prima utilizada na secagem deste projeto, contribuindo de alguma forma para $o$ trabalho. 